\title{
IMPLEMENTASI TECHNIQUE FOR ORDER PREFERENCES BY SIMILARY TO IDEAL SOLUTION (TOPSIS) PADA SELEKSI ASISTEN LABORATORIUM (Studi kasus : Laboratorium RPL FMIPA Universitas Mulawarman)
}

\author{
Abdul Rasyid ${ }^{1)}$, Septya Maharani' ${ }^{2)}$ \\ ${ }^{1,2)}$ Program Studi Ilmu Komputer, FKTI, Universitas Mulawarman \\ Email : Rasyacool@ymail.com ${ }^{1)}$, Septyamaharani@yahoo.com²)
}

\begin{abstract}
ABSTRAK
Praktikum merupakan kegiatan akademik yang bertujuan untuk membantu Mahasiswa mengikuti praktikum yang disebut praktikan dalam memperdalam ilmu dengan mempraktekkan teori yang dituntun oleh asisten laboratorium. Pemilihan asisten laboratorium yang baru di program studi Ilmu Komputer harus sesuai dengan kemampuan calon asisten dengan praktikum matakuliah yang akan diajarkan, masalah dalam pemilihan calon asisten itu sendiri biasanya terjadi saat admin yaitu asisten kepala laboratorium dalam menilai setiap calon asisten apabila setiap calon memiliki kemampuan yang tidak jauh berbeda dengan calon asisten yang lain. Maka dari itu diperlukan suatu sistem yang dapat membantu admin dalam menilai para calon asisten. Sistem Pendukung Keputusan (SPK) sebagai sistem komputer yang mengolah data menjadi informasi untuk mengambil dari masalah semi terstruktur yang spesifik sangat cocok dalam pengambilan keputusan. Salah satu metode yang dipakai didalam SPK ialah metode Technique For Order Preference by Similarity to Ideal Solution (TOPSIS) dimana alternatif yang dipilih memiliki kedekatan dengan solusi ideal positif dan jauh dari solusi ideal negatif. Hasil yang dicapai dari penelitian ini menerapkan metode Technique For Order Preference by Similarity to Ideal Solution dalam sistem pendukung keputusan yang dapat memberikan rekomendasi calon asisten kepada admin sebagai bahan pertimbangan untuk pengambilan keputusan secara tepat dan diharapkan dapat mempermudah proses keputusan yang terbaik.
\end{abstract}

Kata kunci : Sistem Pendukung Keputusan, Asisten Laboratorium, TOPSIS.

\section{PENDAhuluan}

Praktikum di Program Studi Ilmu Komputer Fakultas Matematika Dan Ilmu Pengetahuan Alam Universitas Mulawarman merupakan kegiatan akademik. Untuk mendukung proses pembelajaran dalam kegiatan praktikum, maka diperlukan tenaga asisten praktikum. Masalah umum yang sering terjadi dalam proses penilaian potensi calon asisten diantaranya adalah subyektifitas dalam pengambilan keputusan, terutama jika beberapa calon asisten yang ada memiliki kemampuan dan beberapa pertimbangan lain yang tidak jauh berbeda. Salah satu cara mengatasi masalah tersebut adalah adanya suatu metode yang dapat memberikan rekomendasi sebagai bahan pertimbangan untuk pengambilan keputusan secara tepat.

Sistem Pendukung Keputusan (SPK) sebagai sistem komputer yang mengolah data menjadi informasi untuk mengambil dari masalah semi terstruktur yang spesifik. Sistem Pendukung Keputusan (SPK) adalah suatu sistem informasi berbasis komputer yang melakukan pendekatan yang menghasilkan berbagai alternatif keputusan untuk membantu pihak tertentu dalam menangani permasalahan dengan menggunakan data dan model. Suatu Sistem pendukung keputusan hanya memberikan alternatif keputusan sehingga dalam mengoptimalkan proses penilaian kompetensi/ potensi dari calon asisten, dibangun sebuah sistem berbasis komputer yang dinamakan sistem pendukung keputusan atau disebut juga Decission Support System (DSS) [1].

Penelitian untuk seleksi asisten laboratorium ini, penulis menerapkan metode Technique For Order Preference by Similarity to Ideal Solution (TOPSIS), dimana alternatif yang dipilih memiliki kedekatan dengan solusi ideal positif dan jauh dari solusi ideal negatif. Solusi ideal terbentuk jika sebagai komposit dari nilai kerja terbaik ditampilkan oleh setiap alternatif untuk setiap atribut. Perhitungan untuk memilih asisten laboratorium yang sesuai dengan kemampuan mahasiswa berdasarkan standar kriteria dan dari hasil tes yang dilakukan sehingga yang terpilih lebih akurat dan sesuai dengan kemampuan mahasiswa [9].

Dari penelitian sebelumnya menyebutkan Implementasi Technique for Order Preference by Similarity to Ideal Solution (TOPSIS) menggunakan prinsip bahwa alternatif yang terpilih harus mempunyai jarak terdekat dari solusi ideal positif dan terjauh dari solusi ideal negatif dari sudut pandang geometris dengan menggunakan jarak Euclidean untuk menentukan kedekatan relatif dari suatu alternatif dengan solusi optimal [7]. 
Sedangkan menurut penelitian lainnya metode Technique for Order Preference by Similarity to Ideal Solution (TOPSIS) adalah salah satu metode yang bisa membantu proses pengambilan keputusan yang optimal untuk menyelesaikan masalah keputusan secara praktis. Hal ini disebabkan karena konsepnya sederhana dan mudah dipahami, komputasinya efisien dan memiliki kemampuan untuk mengukur kinerja relatif dari alternatif-alternatif keputusan dalam bentuk matematis yang sederhana [11].

Berdasarkan yang telah dipaparkan, maka penulis mengambil judul penelitian ini adalah "Implementasi Technique for Order Preference by Similarity to Ideal Solution (TOPSIS) Pada Seleksi Asisten Laboratorium" yang dapat memberikan rekomendasi sebagai bahan pertimbangan untuk pengambilan keputusan secara tepat dan diharapkan dapat mempermudah proses keputusan yang terbaik.

\section{TINJAUAN PUSTAKA}

\subsection{Sistem Pendukung Keputusan}

Sistem Pendukung Keputusan (SPK) adalah suatu sistem informasi berbasis komputer yang melakukan pendekatan untuk menghasilkan berbagai alternatif keputusan untuk membantu pihak tertentu dalam menangani permasalahan dengan menggunakan data dan model. Suatu SPK hanya memberikan alternatif keputusan dan selanjutnya diserahkan kepada user untuk mengambil keputusan [1]. Pengambilan keputusan merupakan hasil suatu proses pemilihan dari berbagai alternatif tindakan yang mungkin dipilih dengan mekanisme tertentu, dengan tujuan untuk menghasilkan keputusan yang terbaik. Dimana proses keputusan secara bertahap, sistematik, konsisten, dan dalam setiap langkah sejak awal telah mengikutsertakan semua pihak, akan memberikan hasil yang baik [14].

\subsection{Sistem Pendukung Keputusan}

Konsep Sistem Pendukung Keputusan (SPK) merupakan sebuah sistem interaktif berbasis komputer yang membantu pembuatan keputusan memanfaatkan data dan model untuk menyelesaikan masalah- masalah yang bersifat tidak terstruktur dan semi terstruktur. Sistem Pendukung Keputusan (SPK) dirancang untuk menunjang seluruh tahapan pembuatan keputusan, yang dimulai dari tahapan mengidentifikasi masalah, memilih data yang relevan, menentukan pendekatan yang digunakan dalam proses pembutan keputusan sampai pada kegiatan mengevaluasi pemilihan alternatif [10].

Adapun karakteristik sistem pendukung keputusan [16] :

1. Sistem pendukung keputusan dirancang untuk membantu pengambil keputusan dalam memecahkan masalah yang sifatnya semi terstruktur ataupun tidak terstruktur.
2. Sistem pendukung keputusan dirancang sedemikian rupa sehingga dapat digunakan dengan mudah oleh orang-orang yang tidak memiliki dasar kemampuan pengoperasian komputer yang tinggi.

3. Sistem pendukung keputusan dirancang dengan menekankan pada aspek fleksibilitas serta kemampuan adaptasi yang tinggi. Sehingga mudah disesuaikan dengan berbagai perubahan lingkungan yang terjadi dalam kebutuhan pemakai.

Dengan berbagai karakter khusus seperti dikemukakan sebelumnya, sistem pendukung keputusan dapat memberikan manfaat atau keuntungan bagi pemakainya. Keuntungan yang dimaksud diantaranya meliputi:

1. Sistem pendukung keputusan memperluas kemampuan pengambil keputusan dalam memproses data/informasi bagi pemakainya.

2. Sistem pendukung keputusan membantu pengambil keputusan dalam hal penghematan waktu yang dibutuhkan untuk memecahkan masalah terutama berbagai masalah yang sangat kompleks dan tidak terstruktur. hasilnya dapat diandalkan.

\subsection{Laboratorium}

Laboratorium adalah wadah untuk melakukan praktek atau penerapan atas teori, penelitian dan pengembangan keilmuan di lingkungan Program Studi Ilmu Komputer Fakultas Matematika Dan Ilmu Pengetahuan Alam, sehingga menjadi unsur penting dalam kegiatan pendidikan dan penelitian, khususnya dibidang komputer dan teknologi. Kegiatan yang ada dalam lingkup pengelolaan laboratorium meliputi praktikum, pengajaran, penggunaan laboratorium untuk penelitian dan kerja sama penelitian atau sejenisnya [4].

Asisten Laboratorium adalah mahasiswa / mahasiswi yang ditunjuk dan ditugaskan oleh Kepala Laboratorium untuk memberikan penjelasan materi praktikum bagi mahasiswa untuk matakuliah tertentu. dan memiliki integritas yang tinggi, disiplin, bertanggungjawab, dan memiliki indeks prestasi baik, serta telah lulus untuk mata kuliah yang bersangkutan [4].

\subsection{Technique For Order Preferences by Similary to Ideal Solution (TOPSIS)}

Technique For Order Preferences by Similary to Ideal Solution (TOPSIS) adalah salah satu metode pengambilan keputusan multikriteria yang pertama kali diperkenalkan oleh Yoon dan Hwang (1981). Dengan ide dasarnya adalah bahwa alternatif yang dipilih memiliki jarak terdekat dengan solusi ideal dan yang yang terjauh dari solusi ideal negatif.

TOPSIS memperhatikan baik jarak ke solusi ideal positif maupun ke solusi ideal negatif dengan mengambil hubungan kedekatan menuju solusi 
ideal. Dengan melakukan perbandingan pada keduanya, urutan pilihan dapat ditentukan [9].

Secara umum, prosedur dari metode TOPSIS mengikuti langkah-langkah :

a. Menentukan matriks keputusan yang ternormalisasi.

b. Menghitung matriks keputusan yang ternormalisasi terbobot.

c. Menghitung matriks solusi ideal positif dan matriks solusi ideal negative.

d. Menghitung jarak antara nilai setiap alternatif dengan matriks solusi ideal positif dan matrik solusi ideal negatif.

e. Menghitung nilai preferensi untuk setiap alternatif

Langkah-langkah yang dilakukan dalam penyelesaian masalah menggunakan metode TOPSIS adalah :

\section{a. Langkah Menghitung Matriks}

Ternormalisasi

Topsis membutuhkan rating kinerja tiap calon asisten pada setiap kriteria atau subkriteria yang ternormalisasi. Matriks ternormalisasi terbentuk dari persamaan 1 :

$$
x_{i j}=\frac{x_{i j}}{\sqrt{\sum_{i=1 x^{2} i j}^{m}}}
$$

\section{b. Langkah Menghitung}

Matriks

Ternormalisasi Terbobot

Persamaan 3 digunakan untuk menghitung matriks ternormalisasi terbobot, maka harus ditentukan terlebih dahulu nilai bobot yang merepresentasikan preferensi absolute dari pengambil keputusan. Nilai bobot preferensi menunjukkan tingkat kepentingan relatif setiap kriteria atau subkriteria pada persamaan 2 :

$$
\begin{aligned}
& \mathrm{w}=\left\{w_{1} w_{2} w_{3} \ldots w_{n}\right\} \\
& y_{i j=} w_{i} r_{i j} \ldots \ldots \ldots \ldots \ldots \ldots
\end{aligned}
$$

\section{c. Langkah Menghitung Matriks Solusi Ideal Positif dan Matriks Solusi Ideal Negatif}

Solusi ideal positif dan solusi ideal negatif dapat ditentukan berdasarkan rating bobot ternormalisasi. Perlu diperhatikan syarat pada persamaan 4 dan 5 agar dapat menghitung nilai solusi ideal dengan terlebih dahulu menentukan apakah bersifat keuntungan (benefit) atau bersifat biaya (cost):

$$
\begin{aligned}
& A^{+}=\left(y_{1}^{+} y_{2}^{+} \ldots y_{n}^{+}\right) ; \\
& A^{-}=\left(y_{1}^{-} y_{2}^{-} \ldots y_{n}^{-}\right) ; .
\end{aligned}
$$

Dimana :

$$
y_{i}^{+} \text {adalah } \max y_{i j} \text {, jika } \mathrm{j} \text { adalah atribut }
$$
keuntungan (benefit) Sedangkan min $y_{i j}$, jika j adalah atribut biaya (cost)

$$
y_{i}^{-} \text {adalah } \min y_{i j} \text {, jika } \mathrm{j} \text { adalah atribut }
$$
keuntungan (benefit) Sedangkan $\max y_{i j}$, jika j adalah atribut biaya (cost)

\section{d. Langkah Menentukan Jarak Antara Nilai Setiap Alternatif Dengan Matriks Solusi Ideal Positif dan Matriks Solusi Ideal Negatif. \\ Separation measure merupakan pengukuran} jarak jauh dari suatu alternatif ke solusi ideal dan solusi ideal negatif. Perhitungan matematisnya adalah sebagai berikut :

- Jarak alternatif $\left(D_{i}^{+}\right)$dengan solusi ideal positif dirumuskan pada persamaan 6

$D_{i}^{+}=\sqrt{\sum_{i=1}^{n}\left(y_{i}^{+}-y_{i j}\right)^{2}}$

- Jarak alternatif $\left(D_{i}^{-}\right)$dengan solusi ideal negatif dirumuskan pada persamaan 7 .

$$
D_{i}^{-}=\sqrt{\sum_{i=1}^{n}\left(y_{i j}-y_{i}^{-}\right)^{2}} \text {. }
$$

- $\quad$ Langkah Menghitung Nilai Preferensi Untuk Setiap Alternatif.

Nilai preferensi $\left(v_{1}\right)$ untuk setiap alternatif dirumuskan dalam persamaan 8 .

$$
v_{1}=\frac{D_{i}}{D_{i}^{-}+D_{i}^{+}}
$$

\subsection{Unified Modeling Language (UML)}

UML adalah bahasa yang telah menjadi standard untuk visualisasi, menetapkan, membangun dan mendokumentasikan artifak suatu sistem perangkat lunak. UML adalah sebuah bahasa yang telah menjadi standar dalam industri untuk visualisasi, merancang dan mendokumentasikan sistem piranti lunak. UML menawarkan sebuah standar untuk merancang model sebuah sistem.

UML adalah sebuah bahasa untuk menentukan, visualisasi, konstruksi, dan mendokumentasikan artifact (bagian dari informasi yang digunakan atau dihasilkan dalam suatu proses pembuatan perangkat lunak). Artifact dapat berupa model, deskripsi atau perangkat lunak dari sistem perangkat lunak, seperti pada pemodelan bisnis dan sistem non perangkat lunak lainnya. 
Berdasarkan beberapa pendapat yang dikemukakan diatas dapat ditarik kesimpulan bahwa Unified Modeling Language adalah sebuah bahasa yang berdasarkan grafik atau gambar untuk menvisualisasikan, menspesifikasikan, membangun dan pendokumentasian dari sebuah sistem pengembangan perangkat lunak berbasis Object Oriented (Hend, 2006).

\section{METODE PENELITIAN}

Penelitian ini menggunakan Sistem Pendukung Keputusan (SPK), Technique for Order Preference by Similarity to Ideal Solution (TOPSIS), Personal Home Page (PHP) dan My Structured Query Language (MySQL) sebagai bahan tinjauan pustaka termasuk teori dasar dan perbandingan dalam hal source code program dan sebagainya sebagai penunjang penelitian agar tidak menyimpang dari kondisi yang ada.

Sistem pendukung keputusan pemilihan asisten laboratorium menggunakan metode Technique for Order Preference by Similarity to Ideal Solution (TOPSIS) ini merupakan aplikasi yang memudahkan Laboran dalam memilih asisten laboratorium sesuai dengan kriteria yang dipilih, serta Admin bisa memasukkan bobot persentase dari setiap kriteria sesuai tingkat kepentingan Laboratorium tersebut.

\section{HASIL DAN PEMBAHASAN}

\subsection{Perancangan Use Case Diagram Sistem}

Perancangan use case diagram merupakan tahap awal dan utama dalam proses pengembangan sistem, dimana dalam tahapan ini dijelaskan dan didefinisikan fungsi-fungsi serta fitur-fitur apa saja yang dapat disediakan oleh sistem. Pada use case diagram mempunyai aktor yaitu admin. Agar lebih jelas bisa dilihat pada gambar 1 .

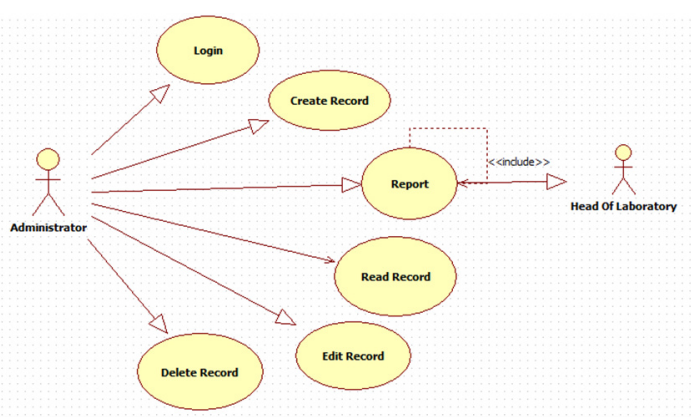

Gambar 1. Use Case Diagram Sistem

\subsection{Perancangan Activity Diagram Sistem}

Diagram pada kategori ini menjelaskan mengenai alur - alur kegiatan yang dapat dilakukan oleh admin terhadap sistem yang telah dikembangkan, berdasarkan use case diagram yang telah dibuat sebelumnya. Pada diagram ini membahas mengenai aktivitas pengguna dan admin bisa dilihat pada gambar 2 .

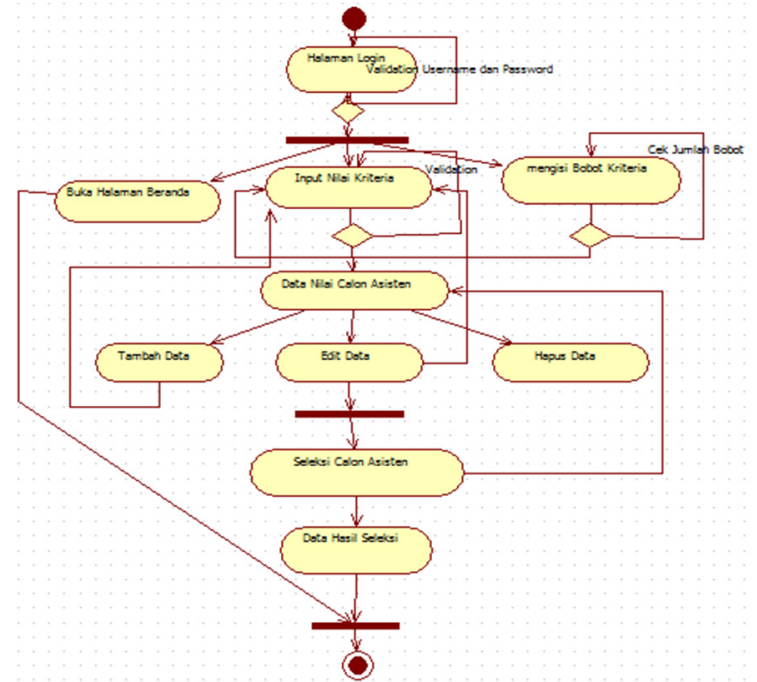

Gambar 2. Activity Diagram Sistem

\subsection{Diagram Alir Implementasi TOPSIS}

Diagram implementasi ini menjelaskan mengenai alur - alur metode TOPSIS terhadap sistem yang telah dikembangkan, Pada diagram ini membahas mengenai aktivitas alur implementasi bisa dilihat pada gambar 3 .

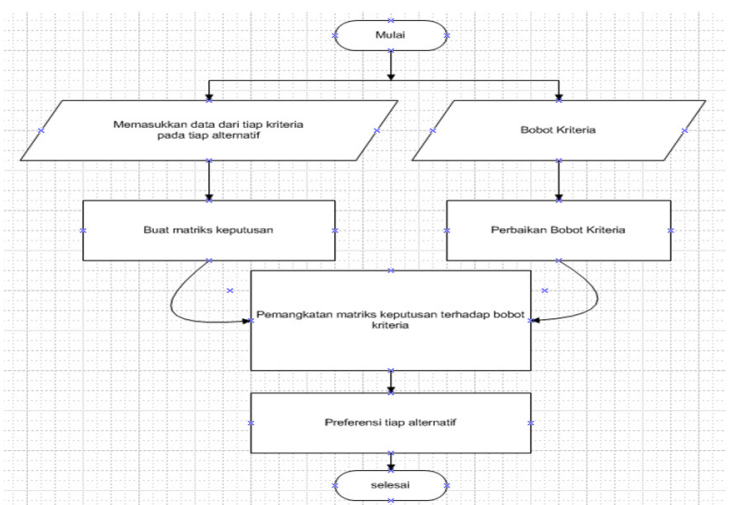

Gambar 3. Diagram Alir Implementasi TOPSIS

\subsection{Implementasi Sistem}

Berikut ini akan dijabarkan hasil implementasi dari sistem yang telah dirancang sebelumnya beserta fungsi-fungsi Content pada setiap Form.

\section{a. Form Login}

Pada Form login terdapat username dan password yang harus diisi oleh admin serta tombol "Login" untuk masuk ke Beranda. Jika username dan password yang diisi admin benar, maka setelah mengklik login admin akan masuk ke halaman Beranda yang terdapat pada gambar 4. 


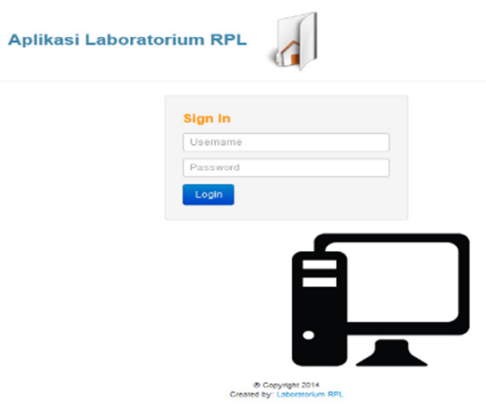

Gambar 4. Form Login

\section{b. Form Input Nilai}

Pada form ini admin dapat menginput nilai setiap calon asisten yang sudah dinilai dengan berbagai kriteria yang telah diikutin dan dinilai oleh kepala laboratorium dan dilanjutkan oleh admin untuk menginputkan nilainya masing - masing yang terdapat pada gambar 5 .

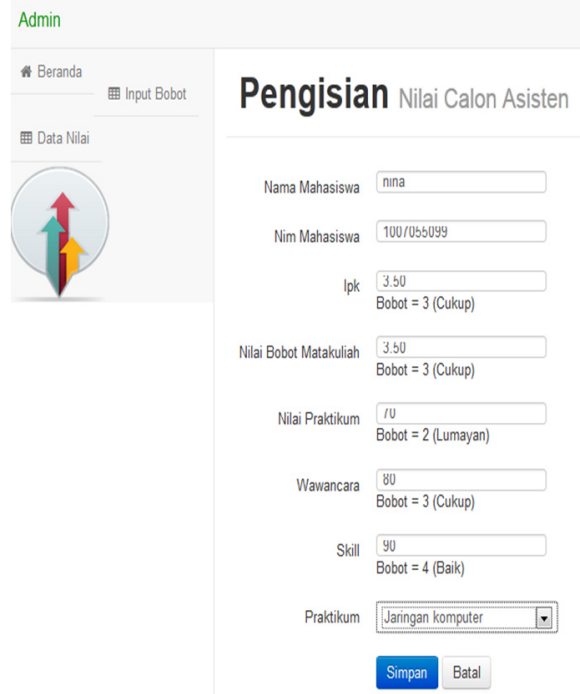

Gambar 5. Form Input Nilai

\section{c. Form Data Nilai}

form ini hasil dari inputan nilai yang diisi oleh admin dan halaman ini dapat menampilkan berbagai nilai masing - masing kriteria oleh setiap calon asisten dan menampilkan hasil perhitungan akhir dengan nilai tertinggi akan diketahui dari beberapa calon tersebut yang terdapat pada gambar 6.

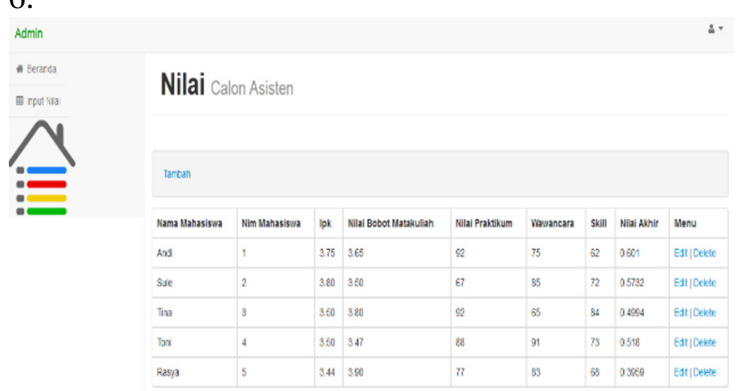

Gambar 6. Form Data Nilai

\subsection{Pengujian}

Di buktikan data uji sebanyak Ada 5

Mahasiswa yang akan menjadi alternatif yaitu:

- $\mathrm{A} 1=$ Andi

- $\mathrm{A} 2=$ Sule

- $\mathrm{A} 3=$ Tina

- $\mathrm{A} 4=\mathrm{T}$ oni

- $\mathrm{A} 5=$ Rasya

Dengan 5 Kriteria yang jadi acuan dalam pengambilan keputusan:

- $\mathrm{C} 1$ = Ipk

- $\mathrm{C} 2$ = Nilai Bobot Mata kuliah

- $\mathrm{C} 3$ = Nilai Praktikum

- $\mathrm{C} 4=$ Wawancara

- $\quad$ C5 = Kemampuan Mengajar / Skill

Di Dapat Matriks Ternormalisasi :

\begin{tabular}{|l|l|l|l|l|l|}
\hline \multicolumn{7}{|c|}{ Matriks Ternormalisasi } \\
\hline \multirow{4}{*}{$R$} & $\mathrm{X} 1$ & $\mathrm{X} 2$ & $\mathrm{X} 3$ & $\mathrm{X} 4$ & $\mathrm{X} 5$ \\
\cline { 2 - 6 } $\mathbf{R}$ & 0.5039 & 0.45 & 0.5625 & 0.3586 & 0.3086 \\
\cline { 2 - 6 } & 0.6299 & 0.3375 & 0.225 & 0.4781 & 0.4629 \\
\cline { 2 - 6 } & 0.378 & 0.5625 & 0.5625 & 0.239 & 0.6172 \\
\cline { 2 - 6 } & 0.378 & 0.225 & 0.45 & 0.5976 & 0.4629 \\
\cline { 2 - 6 } & 0.252 & 0.5625 & 0.3375 & 0.4781 & 0.3086 \\
\hline
\end{tabular}

Matriks Ternormalisasi Terbobot

Didapatkan dari Perkalian Matriks $\mathbf{R}$ dengan

Bobot Preferensi ( 5, 3, 4, 4, 2 )

\begin{tabular}{|l|l|l|l|l|l|}
\hline \multicolumn{6}{|c|}{ Matriks Ternormalisasi Terbobot } \\
\hline \multirow{4}{*}{$\mathbf{4}$} & $\mathrm{X} 1$ & $\mathrm{X} 2$ & $\mathrm{X} 3$ & $\mathrm{X} 4$ & $\mathrm{X} 5$ \\
\cline { 2 - 6 } & 2.52 & 1.35 & 2.25 & 1.4344 & 0.6172 \\
\cline { 2 - 6 } & 3.1459 & 1.0125 & 0.9 & 1.9124 & 0.9258 \\
\cline { 2 - 6 } & 1.89 & 1.6875 & 2.25 & 0.956 & 1.2344 \\
\cline { 2 - 6 } & 1.89 & 0.675 & 1.8 & 2.3904 & 0.9258 \\
\cline { 2 - 6 } & 1.26 & 1.6875 & 1.35 & 1.9124 & 0.6172 \\
\hline
\end{tabular}

Maka didadapat Solusi Ideal Positif

$\mathrm{y}_{1}{ }^{+}=\operatorname{Max}\{2.52 ; 3.1459 ; 1.89 ; 1.89$; $1.26\}=3.1459$

$\mathrm{y}_{2}{ }^{+}=\operatorname{Max}\{1.35 ; 1.0125 ; 1.6875$;

$0.675 ; 1.6875\}=1.6875$

$\mathrm{y}_{3}{ }^{+}=\operatorname{Max}\{2.52 ; 0.9 ; 2.25 ; 1.8 ; 1.35$

\}$=2.25$

$\mathrm{y}_{4}{ }^{+}=\operatorname{Max}\{1.4344 ; 1.9124 ; 0.956$;

$2.3904 ; 1.9124\}=2.3904$

$\mathrm{y}_{5}{ }^{+}=\operatorname{Max}\{0.6172 ; 0.9258 ; 1.2344$;

$0.9258 ; 0.6172\}=1.2344$

$A^{+}=\{3.1459 ; 1.6875 ; 2.25 ; 2.3904$

; 1.2344$\}$

Solusi Ideal Negatif

$\mathrm{y}_{1}{ }^{-}=\operatorname{Min}\{2.52 ; 3.1459 ; 1.89 ; 1.89$;

$1.26\}=1.26$

$\mathrm{y}_{2}{ }^{-}=\operatorname{Min}\{1.35 ; 1.0125 ; 1.6875$;

$0.675 ; 1.6875\}=0.675$

$\mathrm{y}_{3}{ }^{-}=\operatorname{Min}\{2.52 ; 0.9 ; 2.25 ; 1.8 ; 1.35$

\}$=0.9$

$\mathrm{y}_{4}{ }^{-}=\operatorname{Min}\{1.4344 ; 1.9124 ; 0.956$;

$2.3904 ; 1.9124\}=0.956$ 


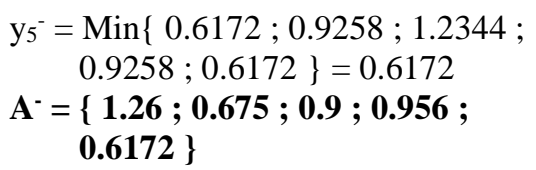

Jarak Antara Nilai Terbobot Positif

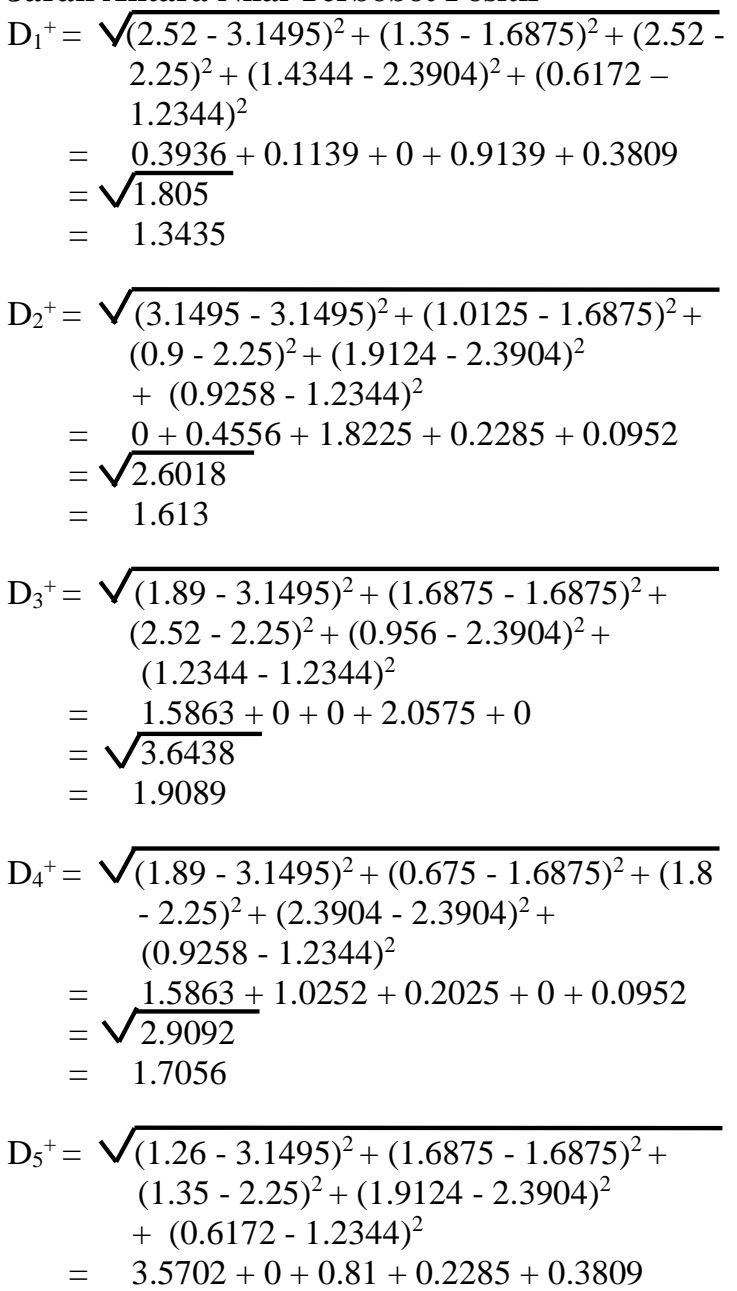

\section{KESIMPULAN}

Dari hasil penelitian yang telah dilakukan oleh penulis, maka dapat diambil beberapa kesimpulan antara lain:

1. Dihasilkan Rancang Bangun Decission Support System dengan metode Technique For Order Preference by Similarity to Ideal Solutionyang mampu melakukan seleksi sebagai rekomendasi pilihan berdasarkan kriteria dan bobot kriteria yang dimasukkan oleh Admin.

2. Sistem ini memberikan informasi mengenai kriteria-kriteria yang menjadi pertimbangan dalam memilih calon asisten laboratorium.

3. Sistem ini mampu menyeleksi sesuai nilai yang didapat yang berasal dari ditentukannya bobot dan kriteria.

4. Berdasarkan data uji program dari 5 calon asisten dipilih $\mathrm{v}_{1}$ yang untuk nilai tertinggi dan kedekatan dengan solusi ideal positif sehingga diambil sebagai calon asisten.

\section{DAFTAR PUSTAKA}

[1] Daihani, D, U. 2001. Komputerisasi Pengambilan Keputusan. Bogor: Ghalia Indonesia.

[2] Dedik Kurniawan, 2005.The Master of 3. Jakarta: Elex Media Komputindo.

[3] Hirin,A.M. 2011.Cepat Mahir Pemrograman Web Dengan PHP dan MySQL, Jakarta : Prestasi Pustaka.

[4] Indarto, K. 2002. Kaitan antara Kegiatan Laboratorium dengan Prestasi Belajar Fisika. Semarang : FMIPA Unnes.

[5] Kadir, Abdul. 2008. Dasar Pemrograman Web Dinamis Menggunakan PHP - Edisi Revisi, ANDI, Yogyakarta.

[6] Kendall. 2003.Analisis dan Perancangan Sistem. Edisi ke-5. Jilid 1. Jakarta : PT. Prehallindo

[7] Kurniawan, Aries, dkk. 2009. Jurusan Ilmu Komputer Program Teknologi Informasi dan Ilmu Komputer Universitas Brawijaya Malang, Indonesia.

[8] Kusrini, 2007. Konsep dan Aplikasi Sistem Pendukung Keputusan, Andi Offset, Yogyakarta

[9] Kusumadewi, Sri, dkk. 2006. Fuzzy Multi Attribute Decision Making. Yogyakarta: Graha Ilmu.

[10] Kosasi, S. 2002. Sistem Penunjang Keputusan (Decision Support System). Pontianak.

[11] Lestari, Sri. (2011). Impelementasi Metode Fuzzy Technique for Order Preference by Similarity to Ideal Solution (TOPSIS) untuk Seleksi Karyawan. Tesis, Magister Ilmu Komputer. Program Pascasarjana, Universitas Gadjah Mada, Yogyakarta.

[12] Widodo, Prabowo Pudjo. 2011.Menggunakan UML, unfied Modeling Language, informatik, Bandung.

[13] Suhendar, A dan Gunadi, H. 2002. Visual Modeling menggunakan UML dan Rational Rose, Bandung : Informatika.

[14] Suryadi, K. dan Ramadhani, M. A.1998. Sistem Pendukung Keputusan: Suatu Wacana Struktural Idealisasi dan Implementasi Pengambilan Keputusan. Bandung: Remaja Rosdakarya Offset.

[15] Suyanto, Asep Herman. 2007. Step by Step: Web Design Theory and Practices. Yogyakarta: Andi Offset.

[16] Turban, E. 2005. Decision Support System and Inteligent Systems. Jilid1. Edisi 7. Yogyakarta: Penerbit Andi. 